\title{
Correlation of Obesity and Dental Caries
}

\author{
Vunnam Sri Sai Charan \\ I year BDS, Saveetha dental Colleges and Hospitals, Saveetha University, P.H Road, Chennai - 600077, India
}

\begin{abstract}
Background: Diets high in sugar have been associated with various health problems such as dental caries, obesity. Obesity is a commonly occurring health problem also associated with an increased frequency of food consumption with a risk of early onset of diabetes, this also has a tendency increase consumption of junk food. This altered food habits might have an effect on the oral cavity resulting in dental caries. Aim: To correlate the obesity and dental caries among individuals aged between 17-25 years. Methods: The individuals were assessed for their weight/height and DMF score. The study was conducted among the individuals aged 17-25 years. Result: The study was conducted to find the relation between the obesity and dental caries. The BMI and DMF could not be correlated.
\end{abstract}

Keywords: BMI, DMF

\section{Introduction}

Obesity is excessive fatthat accumulates in adipose tissue to the extent that health may be adversely affected ${ }^{[1]}$. Obesity causes or exacerbates many health problems, both independently and in association with other diseases. It is associated with the development of type 2 diabetes mellitus, coronary heart disease, an increased incidence of certain forms of cancer, respiratory complications (obstructive sleep apnea) and osteoarthritis of large and small joints. ${ }^{[2,3]}$.Obesity is related to several aspects of oral health, such as caries, periodontitis and xerostomia. ${ }^{[2,4]}$.Dental caries is one of the chronic infectious disease. Cause of dental caries is due to the breakdown of hard tissues like enamel, dentin and cementum. This occurs due to acid made from food debris or sugar on the tooth surface. (Simple sugars in food are these bacteria's primary energy source and thus a diet high in simple sugar is a risk factor). (BMI) means body mass index it is a value derived from the height and weight and it is expressed as $\mathrm{kg} / \mathrm{m}^{2}$.

\section{Materials and Methods}

Obesity is associated with increased frequency of food consumption which is also an risk factor for dental caries Hence the present study was designed to assess the correlation between dental caries and obesity. The study was conducted among the individuals aged 17-25 years. Convenient sample size of 100 dental students of first year informed consent was obtained from them they were about 25 male students and female consisted of 75 students. Height and weight was measured for each of the students. Body mass index (BMI) was calculated using the standard formula-mass $(\mathrm{kg}) / \mathrm{height}(\mathrm{m})^{\wedge} 2$. A Pearson correlation test was conducted to determine the relationship between BMI and DMF.

\section{Result}

A random of 100 students in the age group of 17 to 25 years of both sexes were randomly related. Out of (100) people Male consisted of (25) students and female consisted of (75) students. Height and weight was measured for all the 100 students. Body mass index (BMI) was calculated using the standard formula.Among studied subjects 11 females and 6 males were underweight, 36 females and 12 males were normal weight, 22 females and 6 males were overweight and coming to the obese people 6 females and 1 male were considered obese .28 female students were overweight and obese, 7 of male students were having overweight and obese. Rest of them are from normal weight and under weight, the average height of the students is $162.89 \pm$ 10.120 , the average weight of the students is $62.17 \pm 12.979$ and the average Body Mass Index (BMI) is $36.57 \pm 23.4595$.

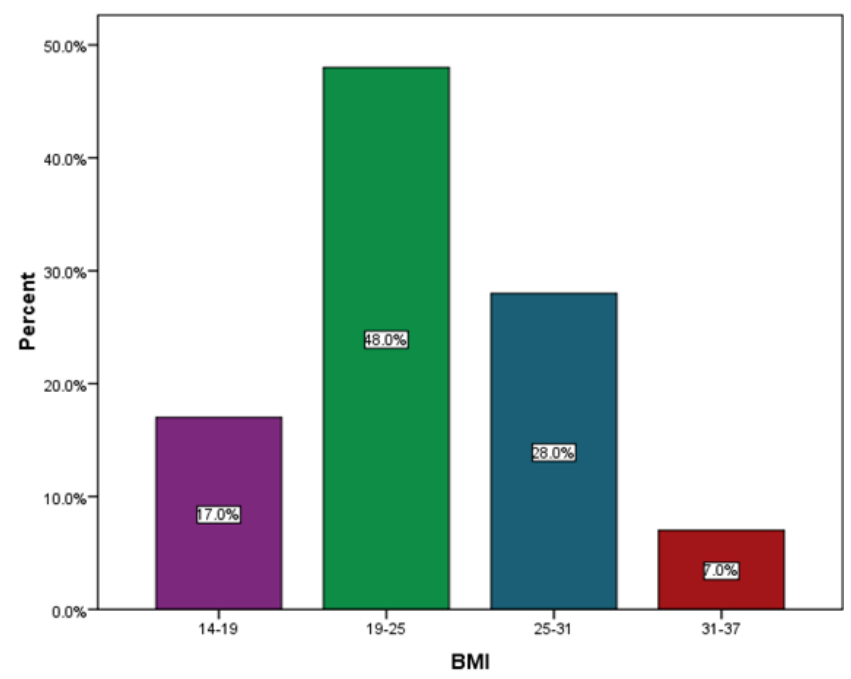

Figure 1: Body Mass Index

The above diagram represents the Body Mass Index (BMI) for the age group of 17-25 years students. The majority $48 \%$ of the students having normal weight, $28 \%$ of the students having over weight followed by $7 \%$ of the students are suffer from obese. Only $17 \%$ are belongs to underweight.

\section{Statistical Analysis}

A Pearson product-moment correlation was run to determine the relationship between an individual's Body Mass Index (BMI) and Decayed Missing Filling tooth (DMF). The data showed that there is no correlation between BMI and DMF (Decayed tooth, Missing tooth and Filling tooth).

\section{Discussion}

Obesity and dental caries are coincidental in many populations, probably due to the common confounding risk

\section{Volume 5 Issue 6, June 2016 www.ijsr.net}




\section{International Journal of Science and Research (IJSR) \\ ISSN (Online): 2319-7064}

Index Copernicus Value (2013): 6.14 | Impact Factor (2015): 6.391

factors such as intake frequency, cariogenic diet, and poor oral health. [5].Dental caries development is the result of an interaction between genetic and environmental factors. The essential process comprises localized destruction of susceptible dental hard tissues by acidic by-products from bacterial carbohydrate fermentation [6].In the present study $48 \%$ ) of the students had normal weight, $28 \%$ of students were overweight and (7\%) of people are obese. In the present study, fatty food consumption was found to more in obese group followed by overweight, normal, and underweight groups. Though it can be assumed that students with high BMI values consume more of fatty foods than students with normal or low BMI [7]. Obesity may also be due to other systemic causes for which the subjects were not evaluated, over all caries prevalence was (1.29\%). The results of this study is lower than few other studies reported $[7,8,9]$. This could be due to either a increased frequency of consumption of foods or a decreased consumption of cariogenic substance. The relationship between being obesity and the presence of dental caries in students is far more complex than can be explained by carbohydrate consumption alone. Though obesity and dental caries are affected by dietary habits. It is not sure as the study did not include a questionnaire on their dietary habits,.48\% of studies have proven that there is no correlation between (BMI) and (DMFT)score , 35\% of studies had proven that there is correlation between BMI and DMFT and 19\% had inverse association between dental caries BMI comes from studies in developing countries and samples with severe dental caries [10].however the present study did not find any correlation between dental caries and obesity.

\section{Conclusion}

The BMI and DMF showed no correlation. This could be due to increased frequency of consumption of foods or a decreased consumption of cariogenic substances.

\section{References}

[1] Obesity: preventing and managing the global epidemic. Report of a WHO consultation. World Health Organ Tech Rep Ser. 2000;894:i-xii. 1-253. [PubMed]

[2] Mathus-Vliegen EM, Nikkel D, Brand HS. Oral aspects of obesity. Int Dent J. 2007;57:249-256. [PubMed]

[3] Kopelman PG. Obesity as a medical problem. Nature. 200635-643. [PubMed]

[4] Saito T, Shimazaki Y, Kiyohara Y, Kato I, Kubo M, Iida M, Yamashita Y. Relationship between obesity, glucose tolerance, and periodontal disease in Japanese women: theHisayama study. J Periodontal Res. 2005;

[5] Hilgers KK, Matthew Akridge BA, Scheetz JP, Kinane DF. Childhood obesity and dental development. Pediatr Dent 2006;28:18-22.

[6] Seow WK. Biological mechanisms of early childhood caries. Commun Dent Oral Epidemiol. 1998;26(1 Suppl):8-27.

[7] CrossRef,PubMed,CAS,Web of Science® Times Cited: 69

[8] Exploring the relation between body mass index, diet, and dental caries among 6-12-year-old children A Elangovan, J Mungara, E Joseph
[9] Department of Pedodontics and Preventive Dentistry, Ragas Dental College and Hospital, Chennai, Tamilnadu, India

[10] Tambelini CA, Ramos DM, Frederico RC, Tomasetti CS, Maciel SM. Dental caries in adolescents and its association with excess weight and sociodemographic factors in Londrina, Parana, Brazil. Rev OdontoCienc2010;25:245-9.

[11] Willershausen B, Haas G, Krummenauer F, Hohenfellner K. Relationship between high weight and caries frequency in German elementary school children. Eur J Med Res 2004;9:400-4.[PUBMED]

[12] Body mass index and dental caries in children and adolescents: a systematic review of literature published 2004 to 2011

[13] Merrilyn Hooley1*, Helen Skouteris1, Cecile Boganin1, Julie Satur2 and Nicky Kilpatrick3,4 